\title{
Review Article \\ DNA Barcoding on Bacteria: A Review
}

\author{
D. E. Lebonah, ${ }^{1}$ A. Dileep, ${ }^{2}$ K. Chandrasekhar, ${ }^{2}$ S. Sreevani, ${ }^{2}$ \\ B. Sreedevi, ${ }^{2}$ and J. Pramoda Kumari ${ }^{2}$ \\ ${ }^{1}$ Department of Biotechnology, Sri Venkateswara University, Tirupati, Andhra Pradesh 517502, India \\ ${ }^{2}$ Department of Microbiology, Sri Venkateswara University, Tirupati, Andhra Pradesh 517502, India
}

Correspondence should be addressed to J. Pramoda Kumari; pramodakumarij@gmail.com

Received 31 May 2014; Revised 30 July 2014; Accepted 30 July 2014; Published 26 August 2014

Academic Editor: Brenda A. Wilson

Copyright (C) 2014 D.E Lebonah et al. This is an open access article distributed under the Creative Commons Attribution License, which permits unrestricted use, distribution, and reproduction in any medium, provided the original work is properly cited.

\begin{abstract}
Bacteria are omnipotent and they can be found everywhere. The study of bacterial pathogens has been happening from olden days to prevent epidemics, food spoilage, losses in agricultural production, and loss of lives. Modern techniques in DNA based species identification are considered. So, there is a need to acquire simple and quick identification technique. Hence, this review article covers the efficacy of DNA barcoding of bacteria. Routine DNA barcoding involves the production of PCR amplicons from particular regions to sequence them and these sequence data are used to identify or "barcode" that organism to make a distinction from other species.
\end{abstract}

\section{Introduction}

Nowadays DNA barcoding has become a justifiable tool for the assessment of global biodiversity patterns and it can allow diagnosis of known species to nontaxonomists [1]. DNA barcoding is a fast, accurate, and standardized method for species level identification, by using short DNA sequences. In 2003, Hebert from the University of Guelph, Ontario, Canada, proposed a new technique called DNA barcoding. Hebert and his associates published a paper entitled "Biological identifications through DNA barcodes". They proposed a new system of species identification, that is, the discovery of species by using a short segment of DNA from a standardized region of the genome. That DNA sequence can be used to identify different species. DNA barcoding is the standardized research that facilitates biodiversity studies like species identification and discovery. This technique helps researchers to understand genetic and evolutionary relationships by assembling molecular, morphological, and distributional data [2]. Species-level identification by DNA barcoding is usually adapted by the recovery of a short DNA sequence from a standard part of the genome [3]. The sequence of barcode from each unknown specimen was then compared with a library of reference barcode sequences obtained from individuals of recognized identity [4]. DNA barcoding is an obligatory tool for species detection and specimen identification [5]. Using standardized identification method is very advantageous for mapping of all the species on Earth, especially when DNA sequencing technology is inexpensively obtainable. The term "DNA barcode" suggests that the standardized DNA sequences can identify taxa in the same way as the 11-digit Universal Product Code identifies retail products in market [6]. Lambert et al. (2005) scrutinized the opportunity of using DNA barcoding to measure the past diversity of the Earth's biota [7].

The barcode of life data system (BOLD) is an informatics workbench assisting the possession, analysis, storage, and publication of DNA barcode records. It links a traditional bioinformatics opening by collecting morphological, molecular, and distributional data. BOLD is freely accessible to any researcher with awareness in DNA barcoding. It helps the assembly of records that meet the standards required to gain barcode designation in the global sequence databases by affording specialized services [8]. BOLD could serve as the universal starting point for identification of species, which would convey users to refer to specialized databases, for example, pathogenic strains, endangered species, and disease vector species [9]. DNA barcoding study 
has been assisted by the barcode of life data system (BOLD), an online resource available to the scientific community (http://www.boldsystems.org). This resource presents tools that let researchers carry out neighbor-joining clustering, to identify taxa using an updated sequence library, among other things, and to store information on the different groups studied [10].

The quarantine barcoding of life (QBOL) aspires to acquire DNA barcode data of important species of bacteria and other organisms to build an analytical tool for quarantine [11]. Species quantification by using the total DNA barcode determines the composition of an insect's bacterial symbionts and how they alter in time, inspecting novel bacterial pathogens of insect pests and assessing hidden biodiversity of soil samples [12-14]. The consortium for the barcode of life (CBOL) was launched in 2004 and now it includes more than 170 member organizations from 50 countries to promote DNA barcoding sensu stricto as the global standard for identification of biological specimens [15].

\section{The Great Criticism on DNA Barcoding}

In the beginning, DNA barcoding was faced with great criticism [16-19] by people who feared that a universal DNAbased approach for species identification will gain exclusivity over traditional methods and taxonomists would go extinct while funding would be vacuumed by high-throughput facilities in order to afford "barcode-species" (i.e., species seen as strings of nucleotides). Even though the major impulsion of DNA barcoding is global bioidentification and its merit is justifiably controversial $[18,20]$, the barcode data can be regarded as phylogeographic in its nature because it places specimens in one or another reciprocally monophyletic groups [21].

\section{DNA Barcoding of Bacteria}

DNA barcoding is intended as a way to catalogue life. This novel method makes use of short but specific DNA tags, or "barcodes" to distinguish one species from another [22]. The majority of species are cryptic in the case of microbes, so barcoding can afford useful information to evaluate ecological sequences and resolve conservation priorities [23].

The study of bacterial pathogens provides a picture of how populations of bacteria act as groups, but with insufficient resolution to see how microorganisms act as individuals but we do not distinguish the minimal number of microbes that instigate infection in a particular organ site. So, it is necessary to produce markers that differentiate between clones in a mixed population during an extended infection. Signature tagged mutagenesis was offered for the behaviour of pools of mutated bacteria and this engages preparing a bank of individual mutants with transposon insertions, each of which has a unique oligonucleotide barcode, allowing the fate of individual mutants to be followed [24-28]. This method has been used widely to identify virulence factors essential for different stages of infection with numerous bacterial pathogens. In addition, it can allow investigators to follow the fate of individual bacteria during infection.

Phytoplasmas are bacterial phytopathogens that produce losses in agricultural production. Makarova et al. (2012), developed a universal DNA barcode based on the elongation factor $\mathrm{Tu}$ (tuf) gene for phytoplasma identification and designed a new set of primers which amplified a 420 $444 \mathrm{bp}$ fragment of tuf from all 91 phytoplasmas strains tested (16S rRNA groups -I through -VII, -IX through XII, -XV, and -XX) [29]. Comparison of neighbor-joining (NJ) trees constructed from the tuf barcode and a $1.2 \mathrm{kbp}$ fragment of the $16 \mathrm{~S}$ ribosomal gene showed that the tuf tree is similar with the 16S rRNA tree and had higher interand intragroup sequence divergence. Mean K2P (Kimura 2parameter distance model) inter-/intragroup divergences of the tuf barcode did not overlap and had approximately one order of magnitude difference for most groups, suggesting the presence of a DNA barcoding gap. They demonstrate that DNA barcoding can be used for identification of phytoplasmas. The tuf barcode performs as well or better than a $1.2 \mathrm{kbp}$ fragment of the $16 \mathrm{~S}$ rRNA gene and thus provides an easy procedure for phytoplasma identification. The use of the tuf barcode allowed separation of main ribosomal groups and most of their subgroups. Phytoplasma tuf barcodes were deposited in the NCBI GenBank and Q-bank databases [29].

A DNA marker that differentiates plant associated bacteria at the species level and below was derived by comparing six sequenced genomes of Xanthomonas, a genus that has many important phytopathogens. This DNA marker consists of a portion of the DnaA replication initiation factor (RIF). Unlike the rRNA genes, DnaA is a single copy gene in the huge majority of sequenced bacterial genomes, and amplification of RIF needs genus-specific primers. The RIF marker is appropriate for the meaningful grouping and classification of strains and presents a greater sequencing success rate than the ITS and a greater number of sequence barcodes than the (internal transcribed spacer) ITS. The RIF marker system should be expandable to most bacterial genera, including Pseudomonas and Xylella [30].

Natalie (2013) tested the consequences of fire on microbial communities in chaparral soils by DNA barcoding and also the comparison of microbes found in burnt and unburned soil samples. The Soil Sample of the chaparral area where there had been a wildfire in May of 2012 was collected and another soil sample collected from around the same elevation where one area was not exposed to the fire. The gene used for DNA barcoding was the $16 \mathrm{~S}$ rRNA gene. For PCR two sets of primers were used, one for bacteria and another for archaea. The DNA was then purified and sub-cloned into the TA plasmid. Sequencing of sixty-two plasmids resulted the DNA data and that was used to search the National DNA database (NCBI) using the blastn program. The idea of this experiment was to discriminate the long-term influence of wildfires on the microbial community found in chaparral soil and ascertained that the archaea microbes found in both the burned and unburned soil samples have similarities. The data shows that the most plentiful microbes found in the unburned samples are much less prominent in the burned samples. Natalie (2013) was able to see a much larger variety in 
the burned samples meaning that many of these soil archaea microbes might had quickly moved in after the fire, after the community instigates to stabilize, these microbes might displaced [31].

Microbial community ecology is an area of fast growth centred within the larger discipline of microbiology. A research team created an artificial microbial community. They used colour-coded enterobacteria taxa transformed with broad-host range plasmids that encoded green fluorescent protein colour variants and developed about microbial fitness. This includes understanding community composition, that the members of a community can respond in different ways to external events and, that these responses can be used to measure fitness. The results measured through pre and post testing and indicated a gain in understanding about microbial communities. Bar coding of selected enterobacterial species using fluorescent proteins provides a simple and speedy method for distinguishing species identity [32].

The influence of bacterial reproductive parasites, for example, Wolbachia, on DNA barcoding remains notorious. Stahlhut et al. (2012) illustrated DNA barcoding as a tool that needs close analysis and taxonomic background knowledge to be understood precisely, analogous to taxonomic keys [33]. By itself, barcode libraries can be precious and helps to identify research questions. In the DNA barcoding literature, however, "democratizing taxonomy" is repeatedly being admired as attainment and a major goal of DNA barcoding [34-36]. Furthermore, although Stahlhut et al. (2012) claimed that DNA barcodes are not used with disregard to other evidence, DNA barcoding studies relying on a single marker are numerous [37-41]. In Michael and Christoph, (2013) opinion, a multilocus sequence typing (MLST) approach could largely reduce the problems that are connected with DNA barcoding as it is presently practiced [42]. MLST-approaches are widely used for the identification of prokaryotes like Wolbachia strains [43]. Therefore, as already recommended by others [44], Michael and Christoph, (2013) powerfully support the inclusion of additional nuclear markers in future barcoding users [42].

In oceans, microbial life is accountable for $98 \%$ of the primary production and the mediation of all the biogeochemical cycles [45]. Microscopic species are the fundamental agents of numerous diseases [46]. Microbiosphere is the unstable and can be dominant at a location or specific time, but rare, and therefore difficult to survey at another time or location. The DNA barcoding of microbial diversity has yet been poorly studied. The rising community genomics [47] and the metagenomics approaches assure great insights on prokaryote biodiversity and molecular evolution [48-52].

Research exploring the community dynamics of microbes relied heavily on gene-centric metagenomic profiling using two genes (16S rRNA and $60 \mathrm{kDa}$ chaperonin protein (cpn60)) to recognize and identify the bacteria. With the framework of the International Barcode of Life, Links et al. (2012) evaluated DNA barcodes for bacteria from the $16 \mathrm{~S}$ rRNA gene and the protein coding cpn60 gene. They found cpn60 universal target having a much larger barcode gap than 16S rRNA suggesting cpn60 as a preferred barcode for Bacteria and that large barcode gap for cpn60 provided a robust target for species-level characterization of data. Assembling consensus sequences for barcodes was shown to be a reliable method for the tracking and identification of novel microbes in metagenomic studies [53].

Accordingly, it is realistic to believe the use of this framework for evaluating barcoding targets for archaea, including 16S rRNA and type II chaperonin (ortholog of cpn60) [54].

Taxonomic identification of biological specimens on basis of DNA sequence information (DNA barcoding) is becoming more and more common in biodiversity science. There are two proposed new computational methods of DNA barcoding and explain a benchmark for bacterial/archeal 16S barcode loci that can be utilized to compare the performance of existing and new methods. The benchmark results also indicated that the taxon coverage of reference sequences is far from complete for genus or species level identification in all the barcode loci observed. Consequently, it is the need to step up the registration of reference barcode sequences to apply high-throughput DNA barcoding to genus or species level identification in biodiversity research [55]. In a reality, the idea of molecular barcoding for taxonomic purposes was reported [56, 57].

Using a molecular operational taxonomic unit (MOTU) system is not only allows the fast and valuable identification of most taxa, as well as those not encountered before, but also allows analysis of the evolution of patterns of diversity. A MOTU approach is also having problems, particularly in the area of choosing what level of molecular difference defines a biologically relevant taxon, but has many benefits. Progress in high-throughput sequencing methodologies, though, place the thought of a universal, multilocus molecular barcoding system in the realm of the possible [58].

DNA barcode approaches enable the generation of complete phylogenetic hypotheses for entire communities of Bacteria by using universal primers $[59,60]$ allowing ecologists to tackle fundamental questions regarding to the processes triggering their distribution and assembly [61, 62]. The status of sequence data among microbiologists has almost certainly been driven by the truth that direct scrutiny of the organisms in these communities is challenging, but also as a consequence of the accessibility of barcode data and tools for studying microbial communities [63]. The most commonly used barcode gene of bacterial and archaeal communities in studies is the small subunit ribosomal 16S rRNA. Innumerable studies had used this marker as a barcode to quantify microbial community structure from environmental samples based on DNA sequences [64]. Those studies suggest that we have only started to scrape the surface of microbial biodiversity; for example, of the millions of bacterial species assessed to exist [65], merely a little part has been illustrated scientifically in existing sequence databases [66]. Researchers allowed addressing ecological questions on more than a few fronts by investigating cryptic diversity through DNA barcoding $[67,68]$.

Liu et al. (2013) wanted to test whether Mollitrichosiphum, an aphid genus with life cycles on subtropical woody host plants, and Buchnera, the primary endosymbiont of aphids, evolve in parallel [69]. Buchnera belongs to the $\gamma$ subdivision of the proteobacteria and is generally believed 
to exist in all aphid species and located in specialized cells, bacteriocytes [70]. They used three aphid genes (mitochondrial COI, cytochrome oxidase subunit I and Cytb, cytochrome b; nuclear EFl $\alpha$, translation elongation factor 1 alpha) and two Buchnera genes (16S rDNA; gnd, gluconate6-phosphate dehydrogenase) to rebuild phylogenies. The similarity between the phylogenetic trees of aphids and Buchnera was then measured. The results show the phylogenetic evidence for the parallel evolution of Mollitrichosiphum and Buchnera at the intraspecific as well as the interspecific levels and it supports the opportunity of using endosymbiont genes to srutinize host evolutionary history and biogeographical patterns. They also explored the exploitability of the Buchnera gnd gene as a barcoding marker for aphid identification. Although their sampling was limited, the study indicates that the Buchnera gnd gene is just as good as COIas a barcoding marker for aphids [69].

\section{Importance of Nanomaterials and CPN Microparticles on DNA Barcoding of Bacteria}

The innovative techniques to identify trace amounts of infectious pathogens quickly, perfectly, and with high sensitivity are in invariable demand to prevent loss of lives and epidemics. Early detection of these pathogens to prevent, treat, and contain the spread of infections is crucial. Adaptable biofunctionalized engineered nanomaterials provide these needs in diagnosing the pathogens in food, blood, and clinical samples. Focusing on the developments of the fluorescent nanoparticles, superparamagnetic nanoparticles and metallic nanostructures is useful for bioimaging, detection of infectious microorganisms, capture infectious virus and bacteria in solutions, food or biological samples in vitro and in vivo [71]. Zhang et al., (2009) developed a fluorescent biobarcoded DNA assay for the rapid detection of the Salmonella enteritidis gene, based on two nanoparticles (NPs): magnetic nanoparticles (MNPs) and gold nanoparticles (Au NP) [72]. Gold/silver/nickel (Au/Ag/Ni) barcoded nanowires demonstrated the multiplexed detection of three antigens that are bio-threat stimulants. They used Bacillus globigii (Bg) spores to simulate $B$. anthracis and other bacterial species [73]. However, large-scale synthesis of high quality barcode nanowires is challenging. Furthermore, complexity in target detection that uses both fluorescence and reflectance imaging modalities will limit the application of this technique in constrained setting environments.

Newly, the progress of molecular imaging and multiplexed bioassays has become growingly important in drug discovery, gene profiling, and clinical diagnostics [74, 75]. Conjugated polymers opened themselves as useful optical platforms to sensitively detect biological and chemical molecules by reason of the signal amplification by a collective system response [76-79]. DNA based self-assembly for fluorescence nanobarcodes deliberated $[80,81]$. Attenuated intracellular bacteria are biodegradable and biocompatible, identified to act as good nonviral means to transfer plasmid DNA into mammalian cells and surfaces of them can be simply modified to accomplish antigen-antibody recognition [82]. Feng et al. (2013) reported a new technique for preparing encoded multicolour conjugated polymer nanoparticles (CPNs) based on the self-assembly of CPNs and bacteria by a simple and time-saving manner. Their bacteria, CPN microparticles, showed multicolour emissions by tuning fluorescence resonance energy transfer (FRET) efficiencies among CPNs under single excitation wavelength and exhibited large stokes shifts up to $170 \mathrm{~nm}$ and they matched well to different excitation sources of fluorescence microscopy, flow cytometry and had been successfully applied for cell imaging and optical barcoding. They said that bacteria-mediated selfassembly for multicolour regulation has not been investigated before for multiplexed bioassays and imaging. They prepared various colour-barcoded microparticles by just mixing the $E$. coli and the CPNs together under one excitation. Four CPNs were prepared with four colours: green, yellow, blue, and red. This new technique was developed for the first time for preparing multicolour CPN-encoded microparticles based on the self-assembly of a noninvasive bacteria (E. coli) and CPNs by just mixing them together. These multicoloured particles exhibited low toxicity towards cells and applied for optical barcoding and cell imaging. This study opens up a new perception in preparing multifunctional structures based on the self-assembly of living organism with functional materials, and it extends the application of water-soluble conjugated polymers in biomedical fields [83].

Diverse severe human infections and some of their symptoms may be induced by different subtypes of Mycobacterium tuberculosis (MTB) like the other pathogens, for example, Nontuberculosis Mycobacteria (NTM). So, effective control of MTB infection and proliferation is required the determination of mycobacterium subtypes. This study develops a novel DNA barcoding visualization method for molecular typing of 17 Mycobacteria genomes published in the NCBI prokaryotic genome database. Three Mycobacterium genes (Rv0279c, Rv3508, and Rv3514) from the PE/PPE family of MT Band were noticed to best represent the interstrain pathogenetic variations. A perfect and fast MTB substrain typing method was recommended based on the combination of the aforementioned three biomarker genes and the 16S rRNA gene and this may also be applied to the other pathogens. In this report, a genomic barcode visualization technology through calculating the base composition of Mycobacterium was built, and screened three genes (Rv0279c, Rv3508, and Rv3514) from the PE/PPE family of MT Band which could be used in Mycobacterium typing. These three genes contained the whole genetic information of Mycobacterium, which had high distinguish ability and combined with $16 \mathrm{~S}$ rRNA gene could attain accurate molecular typing. In the future, this genotyping research will support the genetic potentials accurately and brings hope for conquer disease caused by Mycobacterium [84].

It is challenge to rapidly identify patients infected with Mycobacterium tuberculosis in resource constrained environments. A vigorous and sensitive proposal that does not require bacterial isolation or culture is critical in making informed diagnostic and therapeutic decisions. Liong et al. (2013) introduced a platform for the detection of nucleic 
acids based on a magnetic barcoding strategy. PCR-amplified Mycobacterial genes are sequence-specifically captured on microspheres, labelled by magnetic nanoprobes and detected by nuclear magnetic resonance. All components are incorporated into a single, small fluidic cartridge for streamlined onchip operation. They used this platform to detect $M$. tuberculosis and identify drug-resistance strains from mechanically processed sputum samples within $2.5 \mathrm{~h}$. United with portable systems, the magnetic barcode assay holds promise to become a sensitive, high-throughput and low-cost platform for pointof-care diagnostics. The magnetic barcode platform is a versatile technology that could be readily applied to other studies and diseases. By changing the probe sequences, it could be a first-response tool to detect pathogens in hospital-acquired infections, food chains, and biodefense [85]. The system could also be a bedside tool to identify genetic mutations in chronic diseases, including cancer, heart diseases and diabetes and applied the platform to detect the single-point mutation in exon 21 of epidermal growth factor receptor which has clinical implications in lung cancer [86]. The barcoding strategy is not limited to magnetic readout, but can be extended to luminescent and plasmonic readouts using quantum dots and gold nanoprobes, respectively [87]. The magnetic barcode assay would then be a really facilitating technology for point-of-care diagnostics [85].

Applying a new integrated technique for envisaging bacterial genomes to recognize novel pathogenicity islands in Helicobacter pylori was done by Wang et al. (2013). A genomic barcode imaging method (converting frequency matrices to grey-scale levels) was intended to visually distinguish origin-specific genomic regions in $\mathrm{H}$. pylori. The complete genome sequences of the six $H$. pylori strains published in the National Centre for Biotechnological Information prokaryotic genome database were scanned and compared to the genome barcodes of Escherichia coli (E. coli) O157: H7 strain EDL933 and a random nucleotide sequence by Wang et al. (2012). The following criteria were applied to recognize potential pathogenicity islands (PAIs): (1) length is greater than 10000 continuous base pairs; (2) barcode distance is distinct from that of the general background, and (3) containing genes with known virulence-related functions (as determined by PfamScan and Blast2GO). Large DNA fragments obtained through horizontal transfer and which bear multiple genes encoding bacterial factors with virulence functions are called PAIs [88]. Genomic barcode imaging represents an effective bioinformatic-based approach for scanning bacterial genomes, such as $H$. pylori, to identify candidate pathogenicity islands (PAIs) [89].

In recent times, the genome of Lactobacillus helveticus DPC4571 was sequenced [90] and made known a dairy organism with significant homology $(75 \%$ of genes are homologous) to a probiotic bacteria $L b$. acidophilus NCFM [91]. This directed O'Sullivan et al. (2009) to imagine that a group of genes could be determined which could define an organism's niche [92].

Comparative analysis revealed that if an organism had homologs to the dairy specific gene set, it probably came from a dairy environment. They propose that this "barcode" of 9 genes will be a useful initial guide to researchers in the
LAB field to indicate an organism's ability to occupy a specific niche. Their objective in this study was to take the differences in the phylogenetically related species, $L b$. helveticus and $L b$. acidophilus, and to investigate if they could define a niche specific gene-set, or a "barcode," which would help inform on the origin of particular strains of LAB. Of the sugar metabolism genes analysed, only one (lba 1689) can be used in their barcode as a gut organism indicator.The gut strain $L b$. acidophilus NCFM and the dairy strain Lb. helveticus DPC4571 share notable genetic relatedness regardless of coming from such differing niches. They performed an all-against-all BLAST search between $L b$. helveticus DPC4571 and Lb. acidophilus NCFM, which identified 626 genes that differed between the two, possible niche identifier genes, with a threshold of $1 e^{-10}$ and greater than $30 \%$ identity for homologue detection and explored each of the 626 genes against an eleven genome group. From this analysis 9 genes emerged as being niche specific, that is, genes which were found solely in organisms associated with the gut or genes found solely in organisms associated with the dairy environment. They observed that these 9 genes were involved in characteristics desirable for gut or dairy survival, namely sugar metabolism, the proteolytic and $\mathrm{R} / \mathrm{M}$ systems and bile-salt hydrolysis. At the same time, to this unbiased bioinformatic test they examined in depth all genes involved in dairy and gut characteristic traits for niche-specific genes and importantly they ended up with the same 9 gene "barcode." These 9 "barcode" genes were further validated by performing wider homology searches, using the same homology detection thresholds to ensure that the gutspecific genes were not present in other dairy organisms and vice versa and the 9 gene "barcode" was maintained.

Certainly this barcode should be incessantly monitored and in advance validated as more genomes are sequenced to uphold its accuracy. Furthermore, all the time there is the potential for dairy organisms to be set up to the gut environment through useful food which may guide to them evolving to survive in this environment, for this purpose also, we should continuously monitor and update the barcode [92].

The great quality of biological systems is heterogeneity. A full perceptive of such systems involves a method for uniquely identifying/tracking individual components and their interactions with each other. Peikon et al. (2014) had developed a new method of uniquely tagging individual cells in vivo with a genetic "barcode," which can be recovered by DNA sequencing, and they demonstrated the viability of this method in bacterial cells. This method should prove helpful in tracking interactions of cells within a network, and/or heterogeneity within complex biological samples. To their knowledge, this was the first illustration of an in vivo barcoding scheme with the prospective to scale to solely label all of the individual cells of an entire tissue or organism [93].

Lim et al. (2009) built a general DNA barcode data processing system, Bio Barcode. It encourages the quick gaining of biological species DNA sequence data to meet global standards by providing specialized services. It makes barcoding inexpensive to target to Asian researchers [94]. 
DNA barcoding can be used as a universal tool for food traceability to identify biological specimens. Although, from a merely technical point of view, it is not completely innovative in few years, it has become widely used [46].

\section{Discussion}

The above findings of research on DNA barcoding of bacteria are very minimal. Despite of all the criticisms on DNA barcoding [16-19], it is used for global bioidentification. Will et al. (2005) and Hickerson et al. (2006) say that the merit of DNA barcoding is justifiably controversial $[18,20]$. But the DNA barcoding is expanding in time to fight back to differentiate "species" that are very similar. Barcoding can be employed as a way for arranging novel compilations stranded on barcode sequences and it perhaps work fine for species that were previously much deliberated [95]. The said findings stated that there is a need to develop this area of research on bacteria to end all the criticisms by using different bacterial markers as "barcodes".

\section{Conclusion}

The present review covers recent innovative developments on bacterial DNA barcoding. DNA barcoding is widely used in world wide. Research on bacterial DNA barcoding is yet very limited and still it is in infancy. So, this area of research has to proceed for future studies. Bacterial DNA Barcoding will be useful for identification of bacterial diseases both in plants and in animals. On the basis of this, treatment for the unspecified or unidentified bacterial diseases will be easier in the future. So, this type of research is needful for the society to get rid of facing hazardous bacterial infections.

\section{Abbreviations}

$\begin{array}{ll}\text { Au NP: } & \text { Gold nanoparticles } \\ \text { Bg: } & \text { Bacillus globigii } \\ \text { BLAST: } & \text { Basic local alignment search tool } \\ \text { BOLD: } & \text { The barcode of life data system } \\ \text { COI: } & \text { Cytocrome oxidase } \\ \text { gnd: } & \text { Gluconate-6-phosphate dehydrogenase } \\ \text { CPNs: } & \text { Conjugated polymer nanoparticles } \\ \text { E. coli: } & \text { Escherichia coli } \\ \text { EF1 } \alpha: & \text { Translation elongation factor 1 alpha } \\ \text { FRET: } & \text { Fluorescence resonance energy transfer } \\ \text { ITS: } & \text { Internal transcibed spacer } \\ \text { K2P: } & \text { Kimura 2-parameter distance } \\ \text { KDa: } & \text { Kilo daltons } \\ \text { cpn60: } & \text { Chaperonine 60 } \\ \text { Lb. acidophilus: } & \text { Lactobacillus acidophilus } \\ \text { Lb. heiviticus: } & \text { Lactobacillus helviticus } \\ \text { MLST: } & \text { Multilocus sequence typing } \\ \text { MOTU: } & \text { Molecular operational taxonomic unit } \\ \text { MTB: } & \text { Mycobacterium tuberculosis } \\ \text { NCBI: } & \text { National Centre for Biotechnology } \\ & \text { Information } \\ \text { NJ trees: } & \text { Neighbor-joining trees }\end{array}$

NPs: Nanoparticles

NTM: Nontuberculosis Mycobacteria

PAIs: Potential pathogenicity islands

PCR: Polymerase chain reaction

QBOL: The quarantine barcoding of life

RIF: Replication initiation factor

Tuf: Elongation factor Tu.

\section{Conflict of Interests}

The authors declare that there is no conflict of interests regarding the publication of this review paper.

\section{References}

[1] M. E. Siddall, F. M. Fontanella, S. C. Watson, S. Kvist, and C. Erséus, "Barcoding bamboozled by bacteria: convergence to metazoan mitochondrial primer targets by marine microbes," Systematic Biology, vol. 58, no. 4, pp. 445-451, 2009.

[2] V. Savolainen, R. S. Cowan, A. P. Vogler, G. K. Roderick, and R. Lane, "Towards writing the encyclopaedia of life: an introduction to DNA barcoding," Philosophical Transactions of the Royal Society B: Biological Sciences, vol. 360, no. 1462, pp. 1805-1811, 2005.

[3] P. D. N. Hebert, A. Cywinska, S. L. Ball, and J. R. DeWaard, "Biological identifications through DNA barcodes," Proceedings of the Royal Society B Biological Sciences, vol. 270, no. 1512, pp. 313-321, 2003.

[4] M. Hajibabaei, G. A. C. Singer, P. D. N. Hebert, and D. A. Hickey, "DNA barcoding: how it complements taxonomy, molecular phylogenetics and population genetics," Trends in Genetics, vol. 23 , no. 4, pp. 167-172, 2007.

[5] J. Bergsten, D. T. Bilton, T. Fujisawa et al., "The effect of geographical scale of sampling on DNA barcoding," Systematic Biology, vol. 61, no. 5, pp. 851-869, 2012.

[6] J. Neigel, A. Domingo, and J. Stake, "DNA barcoding as a tool for coral reef conservation," Coral Reefs, vol. 26, no. 3, pp. 487499, 2007.

[7] D. M. Lambert, A. Baker, L. Huynen, O. Haddrath, P. D. N. Hebert, and C. D. Millar, "Is a large-scale DNA-based inventory of ancient life possible?" Journal of Heredity, vol. 96, no. 3, pp. 279-284, 2005.

[8] S. Ratnasingham and P. D. N. Hebert, "BOLD: the barcode of life data system: (http://www.barcodinglife.org)," Molecular Ecology Notes, vol. 7, no. 3, pp. 355-364, 2007.

[9] S. L. Ball and K. F. Armstrong, "DNA barcodes for insect pest identification: a test case with tussock moths (Lepidoptera: Lymantriidae)," Canadian Journal of Forest Research, vol. 36, no. 2, pp. 337-350, 2006.

[10] C. P. Amanda and M. Luciane, "DNA barcoding and traditional taxonomy unified through integrative taxonomy: a view that challenges the debate questioning both methodologies," Biota Neotropica, vol. 10, no. 2, pp. 339-346, 2010.

[11] P. Bonants, E. Groenewald, J. Y. Rasplus et al., "QBOL: a new EU project focusing on DNA barcoding of quarantine organisms," EPPO Bulletin, vol. 40, no. 1, pp. 30-33, 2010.

[12] E. A. Hugo, S. L. Chown, and M. A. McGeoch, "The microarthropods of sub-Antarctic Prince Edward Island: a quantitative assessment," Polar Biology, vol. 30, no. 1, pp. 109$119,2006$. 
[13] A. Juen and M. Traugott, "Amplification facilitators and multiplex PCR: tools to overcome PCR-inhibition in DNA-gutcontent analysis of soil-living invertebrates," Soil Biology \& Biochemistry, vol. 38, no. 7, pp. 1872-1879, 2006.

[14] A. Juen and M. Traugott, "Revealing species-specific trophic links in soil food webs: Molecular identification of scarab predators," Molecular Ecology, vol. 16, no. 7, pp. 1545-1557, 2007.

[15] S. E. Miller, "Proposed standards for BARCODE records in INSDC (BRIs)," in Request document for continuation of support by the Alfred P. Sloan Foundation submitted by the Smithsonian Institution on behalf of Consortium for the barcode of Life: 22 January 2006 Robert H, pp. 36-38, 2005.

[16] D. Rubinoff, "Utility of mitochondrial DNA barcodes in species conservation," Conservation Biology, vol. 20, no. 4, pp. 10261033, 2006.

[17] D. Rubinoff, S. Cameron, and K. Will, "A genomic perspective on the shortcomings of mitochondrial DNA for "barcoding" identification," Journal of Heredity, vol. 97, no. 6, pp. 581-594, 2006.

[18] K. W. Will, B. D. Mishler, and Q. D. Wheeler, "The perils of DNA barcoding and the need for integrative taxonomy," Systematic Biology, vol. 54, no. 5, pp. 844-851, 2005.

[19] K. W. Will and D. Rubinoff, "Myth of the molecule: DNA barcodes for species cannot replace morphology for identification and classification," Cladistics, vol. 20, no. 1, pp. 47-55, 2004.

[20] M. J. Hickerson, C. P. Meyer, and C. Moritz, "DNA barcoding will often fail to discover new animal species over broad parameter space," Systematic Biology, vol. 55, no. 5, pp. 729-739, 2006.

[21] L. B. Beheregaray, "Twenty years of phylogeography: the state of the field and the challenges for the Southern Hemisphere," Molecular Ecology, vol. 17, no. 17, pp. 3754-3774, 2008.

[22] J. M. Guerra-Garcia, F. Espinosa, and J. C. Garcia-Gomez, "Trends in Taxonomy today: an overview about the main topics," Zoological Baetica, vol. 19, pp. 15-49, 2008.

[23] D. Begerow, H. Nilsson, M. Unterseher, and W. Maier, "Current state and perspectives of fungal DNA barcoding and rapid identification procedures," Applied Microbiology and Biotechnology, vol. 87, no. 1, pp. 99-108, 2010.

[24] S. L. Chiang and J. J. Mekalanos, "Use of signature-tagged transposon mutagenesis to identify Vibrio cholerae genes critical for colonization," Molecular Microbiology, vol. 27, no. 4, pp. 797805,1998 .

[25] A. J. Darwin and V. L. Miller, "Identification of Yersinia enterocolitica genes affecting survival in an animal host using signaturetagged transposon mutagenesis," Molecular Microbiology, vol. 32, no. 1, pp. 51-62, 1999.

[26] P. H. Edelstein, M. A. C. Edelstein, F. Higa, and S. Falkow, "Discovery of virulence genes of Legionella pneumophila by using signature tagged mutagenesis in a guinea pig pneumonia model," Proceedings of the National Academy of Sciences of the United States of America, vol. 96, no. 14, pp. 8190-8195, 1999.

[27] M. Hensel, J. E. Shea, C. Gleeson, M. D. Jones, E. Dalton, and D. W. Holden, "Simultaneous identification of bacterial virulence genes by negative selection," Science, vol. 269, no. 5222, pp. 400403, 1995.

[28] J. Mecsas, I. Bilis, and S. Falkow, "Identification of attenuated Yersinia pseudotuberculosis strains and characterization of an orogastric infection in $\mathrm{BALB} / \mathrm{c}$ mice on day 5 postinfection by signature-tagged mutagenesis," Infection and Immunity, vol. 69, no. 5, pp. 2779-2787, 2001.
[29] O. Makarova, N. Contaldo, S. Paltrinieri, G. Kawube, A. Bertaccini, and M. Nicolaisen, "DNA barcoding for identification of "Candidatus phytoplasmas" using a fragment of the elongation factor Tu gene," PLoS ONE, vol. 7, no. 12, Article ID e52092, 2012.

[30] K. L. Schneider, G. Marrero, A. M. Alvarez, and G. G. Presting, "Classification of plant associated bacteria using RIF, a computationally derived DNA marker," PLoS ONE, vol. 6, no. 4, Article ID e18496, 2011.

[31] J. W. W. Natalie, "Determining the microbial diversity in chaparral soils before and after wildfires through DNA barcoding," Project Number-S1119, California State Science Fair, Project Summary, 2013.

[32] L. Thao, T. James, B. Alexandra et al., "Bar-coded Enterobacteria: an undergraduate microbial ecology laboratory module," The American Journal of Educational Research, vol. 1, no. 1, pp. 26-30, 2013.

[33] J. K. Stahlhut, J. Gibbs, C. S. Sheffield, M. A. Smith, and L. Packer, "Wolbachia (Rickettsiales) infections and bee (Apoidea) barcoding: a response to Gerth et al," Systematics and Biodiversity, vol. 10, no. 4, pp. 395-401, 2012.

[34] P. D. N. Hebert and T. R. Gregory, "The promise of DNA barcoding for taxonomy," Systematic Biology, vol. 54, no. 5, pp. 852-859, 2005.

[35] M. Holloway, “Democratizing taxonomy," Conservation in Practice, vol. 7, pp. 14-21, 2006.

[36] D. H. Janzen, W. Hallwachs, P. Blandin et al., "Integration of DNA barcoding into an ongoing inventory of complex tropical biodiversity," Molecular Ecology Resources, vol. 9, no. 1, pp. 1-26, 2009.

[37] A. Hausmann, G. Haszprunar, A. H. Segerer, W. Speidel, G. Behounek, and P. D. N. Hebert, "Now DNA-barcoded: the butterflies and larger moths of Germany," Spixiana, vol. 34, no. 1, pp. 47-58, 2011.

[38] K. N. Magnacca and M. J. F. Brown, "DNA barcoding a regional fauna: Irish solitary bees," Molecular Ecology Resources, vol. 12, no. 6, pp. 990-998, 2012.

[39] C. S. Sheffield, P. D. N. Hebert, P. G. Kevan, and L. Packer, "DNA barcoding a regional bee (Hymenoptera: Apoidea) fauna and its potential for ecological studies," Molecular Ecology Resources, vol. 9, no. 1, pp. 196-207, 2009.

[40] H. R. Taylor and W. E. Harris, "An emergent science on the brink of irrelevance: a review of the past 8years of DNA barcoding," Molecular Ecology Resources, vol. 12, no. 3, pp. 377-388, 2012.

[41] A. Zaldívar-Riverón, J. J. Martínez, F. S. Ceccarelli et al., "DNA barcoding a highly diverse group of parasitoid wasps (Braconidae: Doryctinae) from a Mexican nature reserve," Mitochondrial DNA, vol. 21, no. 1, pp. 18-23, 2010.

[42] G. Michael and B. Christoph, "A multilocus sequence typing (MLST) approach to diminish the problems that are associated with DNA barcoding: a reply to Stahlhut etal. 2012," Systematics and Biodiversity, vol. 11, no. 1, pp. 15-17, 2013.

[43] L. Baldo, J. C. D. Hotopp, K. A. Jolley et al., "Multilocus sequence typing system for the endosymbiont Wolbachia pipientis," Applied and Environmental Microbiology, vol. 72, no. 11, pp. 7098-7110, 2006.

[44] J. R. Dupuis, A. D. Roe, and F. A. H. Sperling, "Multi-locus species delimitation in closely related animals and fungi: one marker is not enough," Molecular Ecology, vol. 21, no. 18, pp. 4422-4436, 2012.

[45] M. L. Sogin, H. G. Morrison, J. A. Huber et al., "Microbial diversity in the deep sea and the underexplored 'rare biosphere", 
Proceedings of the National Academy of Sciences of the United States of America, vol. 103, no. 32, pp. 12115-12120, 2006.

[46] A. Galimberti, F. de Mattia, A. Losa et al., "DNA barcoding as a new tool for food traceability," Food Research International, vol. 50, no. 1, pp. 55-63, 2013.

[47] E. F. DeLong, C. M. Preston, T. Mincer et al., "Community genomics among stratified microbial assemblages in the ocean's interior," Science, vol. 311, no. 5760, pp. 496-503, 2006.

[48] E. F. DeLong, "Microbial population genomics and ecology: the road ahead," Environmental Microbiology, vol. 6, no. 9, pp. 875878, 2004.

[49] M. Leclerc, C. Juste, P. Marteau, R. Nalin, H. Blottiere, and J. Dore, "Intestinal metagenomics and nutrition," Annuals of Nutrition and Metabolism, vol. 51, supplement 1, no. 13, 2007.

[50] S. G. Tringe, C. Von Mering, A. Kobayashi et al., "Comparative metagenomics of microbial communities," Science, vol. 308, no. 5721, pp. 554-557, 2005.

[51] G. W. Tyson, J. Chapman, P. Hugenholtz et al., "Community structure and metabolism through reconstruction of microbial genomes from the environment," Nature, vol. 428, no. 6978, pp. 37-43, 2004.

[52] J. C. Venter, K. Remington, J. F. Heidelberg et al., "Environmental genome shotgun sequencing of the sargasso sea," Science, vol. 304, no. 5667, pp. 66-74, 2004.

[53] M. G. Links, T. J. Dumonceaux, S. M. Hemmingsen, and J. E. Hill, "The Chaperonin-60 Universal Target Is a Barcode for Bacteria That Enables De Novo Assembly of Metagenomic Sequence Data," PLoS ONE, vol. 7, no. 11, Article ID e49755, 2012.

[54] B. Chaban and J. E. Hill, "A 'universal' type II chaperonin PCR detection system for the investigation of Archaea in complex microbial communities," International Society for Microbial Ecology, vol. 6, no. 2, pp. 430-439, 2012.

[55] A. S. Tanabe and H. Toju, "Two new computational methods for universal DNA barcoding: a benchmark using barcode sequences of bacteria, archaea, animals, fungi, and land plants," PLOS ONE, vol. 8, no. 10, Article ID e76910, 2013.

[56] L. B. Mark, "Molecular systematics: counting angels with DNA," Nature, vol. 421, no. 6919, pp. 122-124, 2003.

[57] M. Blaxter and R. Floyd, "Molecular taxonomics for biodiversity surveys: already a reality," Trends in Ecology and Evolution, vol. 18, no. 6, pp. 268-269, 2003.

[58] M. L. Blaxter, "The promise of a DNA taxonomy," Philosophical Transactions of the Royal Society B: Biological Sciences, vol. 359, no. 1444, pp. 669-679, 2004.

[59] A. Barberán and E. O. Casamayor, "Global phylogenetic community structure and $\beta$-diversity patterns in surface bacterioplankton metacommunities," Aquatic Microbial Ecology, vol. 59, no. 1, pp. 1-10, 2010.

[60] J. Wang, J. Soininen, J. He, and J. Shen, "Phylogenetic clustering increases with elevation for microbes," Environmental Microbiology Reports, vol. 4, no. 2, pp. 217-226, 2012.

[61] N. Mouquet, V. Devictor, C. N. Meynard et al., "Ecophylogenetics: advances and perspectives," Biological Reviews, vol. 87, no. 4, pp. 769-785, 2012.

[62] C. O. Webb, D. D. Ackerly, M. A. McPeek, and M. J. Donoghue, "Phylogenies and community ecology," Annual Review of Ecology and Systematics, vol. 33, pp. 475-505, 2002.

[63] N. R. Pace, "A molecular view of microbial diversity and the biosphere," Science, vol. 276, no. 5313, pp. 734-740, 1997.

[64] P. Hugenholtz, B. M. Goebel, and N. R. Pace, "Impact of cultureindependent studies on the emerging phylogenetic view of bacterial diversity," Journal of Bacteriology, vol. 180, no. 18, pp. 4765-4774, 1998.

[65] T. P. Curtis, W. T. Sloan, and J. W. Scannell, "Estimating prokaryotic diversity and its limits," Proceedings of the National Academy of Sciences of the United States of America, vol. 99, no. 16, pp. 10494-10499, 2002.

[66] D. Wu, P. Hugenholtz, K. Mavromatis et al., "A phylogenydriven genomic encyclopaedia of Bacteria and Archaea," Nature, vol. 462, no. 7276, pp. 1056-1060, 2009.

[67] J. B. H. Martiny, B. J. M. Bohannan, J. H. Brown et al., "Microbial biogeography: putting microorganisms on the map," Nature Reviews Microbiology, vol. 4, no. 2, pp. 102-112, 2006.

[68] D. R. Nemergut, E. K. Costello, M. Hamady et al., "Global patterns in the biogeography of bacterial taxa," Environmental Microbiology, vol. 13, no. 1, pp. 135-144, 2011.

[69] L. Liu, X. Huang, R. Zhang, L. Jiang, and G. Qiao, "Phylogenetic congruence between Mollitrichosiphum (Aphididae: Greenideinae) and Buchnera indicates insect-bacteria parallel evolution," Systematic Entomology, vol. 38, no. 1, pp. 81-92, 2013.

[70] P. Buchner, Endosymbiosis of Animals with Plant Microorganisms, Interscience, New York, NY, USA, 1965.

[71] P. Tallury, A. Malhotra, L. M. Byrne, and S. Santra, "Nanobioimaging and sensing of infectious diseases," Advanced Drug Delivery Reviews, vol. 62, no. 4-5, pp. 424-437, 2010.

[72] D. Zhang, D. J. Carr, and E. C. Alocilja, "Fluorescent biobarcode DNA assay for the detection of Salmonella enterica serovar Enteritidis," Biosensors and Bioelectronics, vol. 24, no. 5, pp. 1377-1381, 2009.

[73] J. B.-H. Tok, F. Y. S. Chuang, M. C. Kao et al., "Metallic striped nanowires as multiplexed immunoassay platforms for pathogen detection," Angewandte Chemie, vol. 45, no. 41, pp. 6900-6904, 2006.

[74] M. Han, X. Gao, J. Z. Su, and S. Nie, "Quantum-dot-tagged microbeads for multiplexed optical coding of biomolecules," Nature Biotechnology, vol. 19, no. 7, pp. 631-635, 2001.

[75] H. Lee, J. Kim, H. Kim, J. Kim, and S. Kwon, "Colour-barcoded magnetic microparticles for multiplexed bioassays," Nature Materials, vol. 9, no. 9, pp. 745-749, 2010.

[76] X. Duan, L. Liu, F. Feng, and S. Wang, "Cationic conjugated polymers for optical detection of DNA methylation, lesions, and single nucleotide polymorphisms," Accounts of Chemical Research, vol. 43, no. 2, pp. 260-270, 2010.

[77] H. Ho, A. Najari, and M. Leclerc, "Optical detection of DNA and proteins with cationic polythiophenes," Accounts of Chemical Research, vol. 41, no. 2, pp. 168-178, 2008.

[78] S. W. Thomas III, G. D. Joly, and T. M. Swager, "Chemical sensors based on amplifying fluorescent conjugated polymers," Chemical Reviews, vol. 107, no. 4, pp. 1339-1386, 2007.

[79] H. N. Kim, Z. Guo, W. Zhu, J. Yoon, and H. Tian, "Recent progress on polymer-based fluorescent and colorimetric chemosensors," Chemical Society Reviews, vol. 40, no. 1, pp. 79-93, 2011.

[80] Y. Li, Y. T. H. Cu, and D. Luo, "Multiplexed detection of pathogen DNA with DNA-based fluorescence nanobarcodes," Nature Biotechnology, vol. 23, no. 7, pp. 885-889, 2005.

[81] H. Özhalici-Ünal and B. A. Armitage, "Fluorescent DNA nanotags based on a self-assembled DNA tetrahedron," ACS Nano, vol. 3, no. 2, pp. 425-433, 2009.

[82] D. Akin, J. Sturgis, K. Ragheb et al., "Bacteria-mediated delivery of nanoparticles and cargo into cells," Nature Nanotechnology, vol. 2, no. 7, pp. 441-449, 2007. 
[83] X. Feng, G. Yang, L. Liu et al., "A convenient preparation of multi-spectral microparticles by bacteria-mediated assemblies of conjugated polymer nanoparticles for cell imaging and barcoding," Advanced Materials, vol. 24, no. 5, pp. 637-641, 2012.

[84] B. Liu, X. Zhang, H. Huang, Y. Zhang, F. Zhou, and G. Wang, "A novel molecular typing method of Mycobacteria based on DNA barcoding visualization," Journal of Clinical Bioinformatics, vol. 4, article 4, 2014.

[85] M. Liong, A. N. Hoang, J. Chung et al., "Magnetic barcode assay for genetic detection of pathogens," Nature Communications, vol. 4, article 1752, 2013.

[86] S. Dufort, M. Richard, S. Lantuejoul, and F. De Fraipont, "Pyrosequencing, a method approved to detect the two major EGFR mutations for anti EGFR therapy in NSCLC," Journal of Experimental and Clinical Cancer Research, vol. 30, no. 1, article 57, 2011.

[87] H. D. Hill and C. A. Mirkin, "The bio-barcode assay for the detection of protein and nucleic acid targets using DTTinduced ligand exchange," Nature Protocols, vol. 1, no. 1, pp. 324336, 2006.

[88] G. Schneider, U. Dobrindt, B. Middendorf et al., "Mobilisation and remobilisation of a large archetypal pathogenicity island of uropathogenic Escherichia coli in vitro support the role of conjugation for horizontal transfer of genomic islands," $B M C$ Microbiology, vol. 11, article 210, 2011.

[89] G. Wang, J. Xu, G. Xu, Y. Zhang, F. Li, and J. Suo, "Predicting a novel pathogenicity island in Helicobacter pylori by genomic barcoding," World Journal of Gastroenterology, vol. 19, no. 30, pp. 5006-5010, 2013.

[90] M. Callanan, P. Kaleta, J. O’Callaghan et al., "Genome sequence of Lactobacillus helveticus, an organism distinguished by selective gene loss and insertion sequence element expansion," Journal of Bacteriology, vol. 190, no. 2, pp. 727-735, 2008.

[91] E. Altermann, W. M. Russell, M. A. Azcarate-Peril et al., "Complete genome sequence of the probiotic lactic acid bacterium Lactobacillus acidophilus NCFM," Proceedings of the National Academy of Sciences of the United States of America, vol. 102, no. 11, pp. 3906-3912, 2005.

[92] O. O’Sullivan, J. O'Callaghan, A. Sangrador-Vegas et al., "Comparative genomics of lactic acid bacteria reveals a niche-specific gene set," BMC Microbiology, vol. 9, article 50, 2009.

[93] I. D. Peikon, D. I. Gizatullina, and A. M. Zador, "In vivo generation of DNA sequence diversity for cellular barcoding," Nucleic Acids Research, 2014.

[94] J. Lim, S. Kim, H. Eo et al., "BioBarcode: a general DNA barcoding database and server platform for Asian biodiversity resources," BMC Genomics, vol. 10, supplement 3, article S8, 2009.

[95] E. Check, "Cowrie study strikes a blow for traditional taxonomy," Nature, vol. 438, no. 7069, pp. 722-723, 2005. 

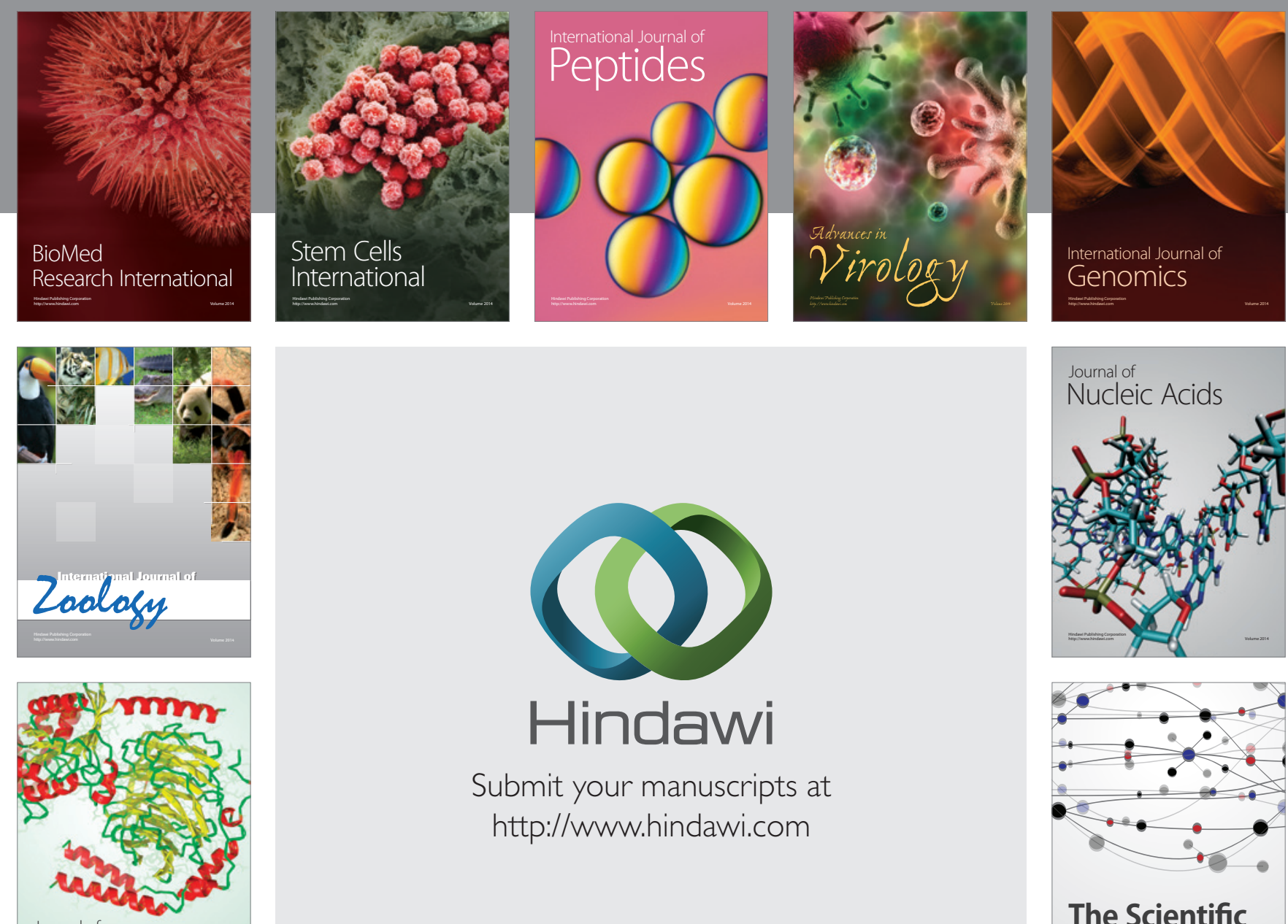

Submit your manuscripts at

http://www.hindawi.com

Journal of
Signal Transduction
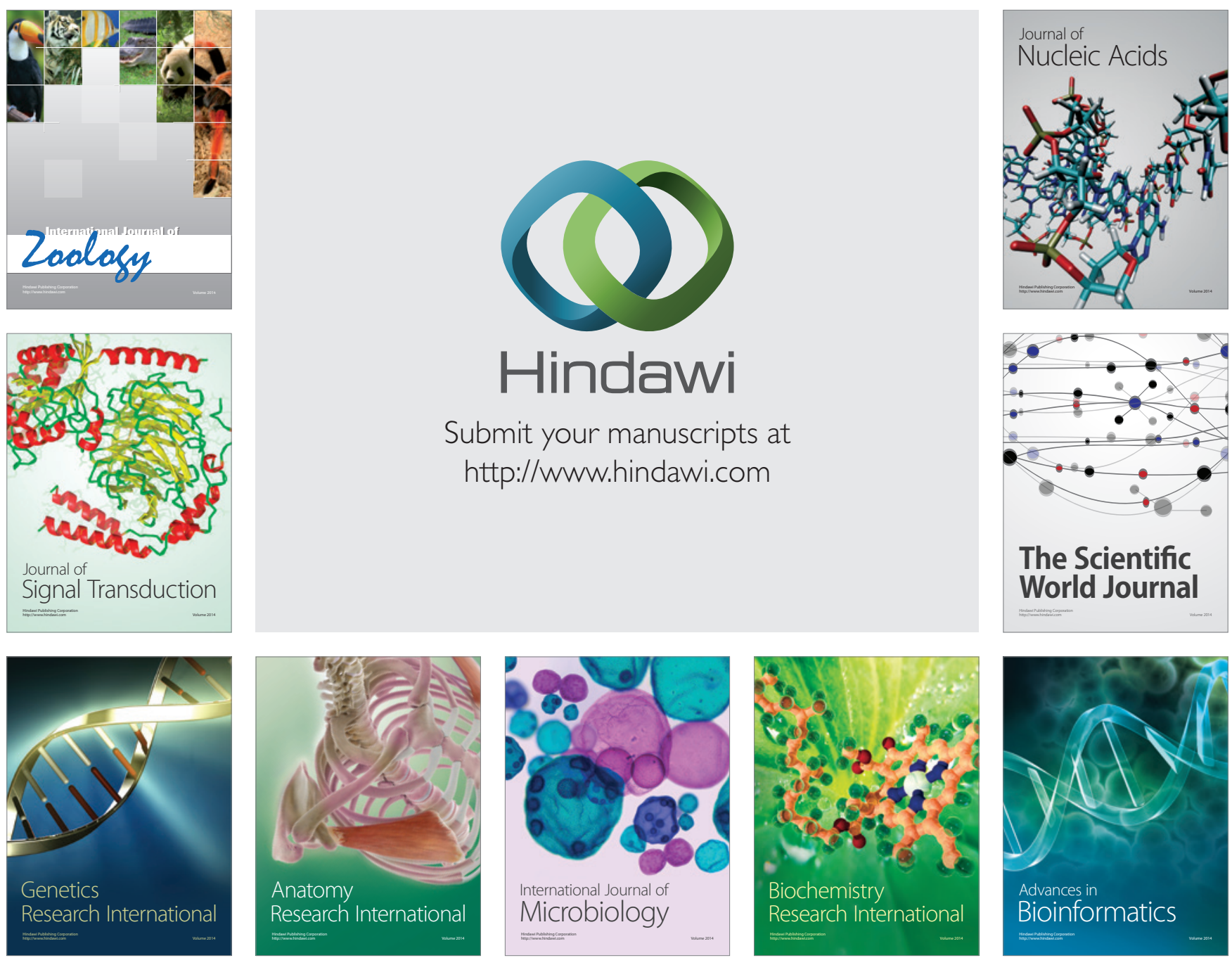

The Scientific World Journal
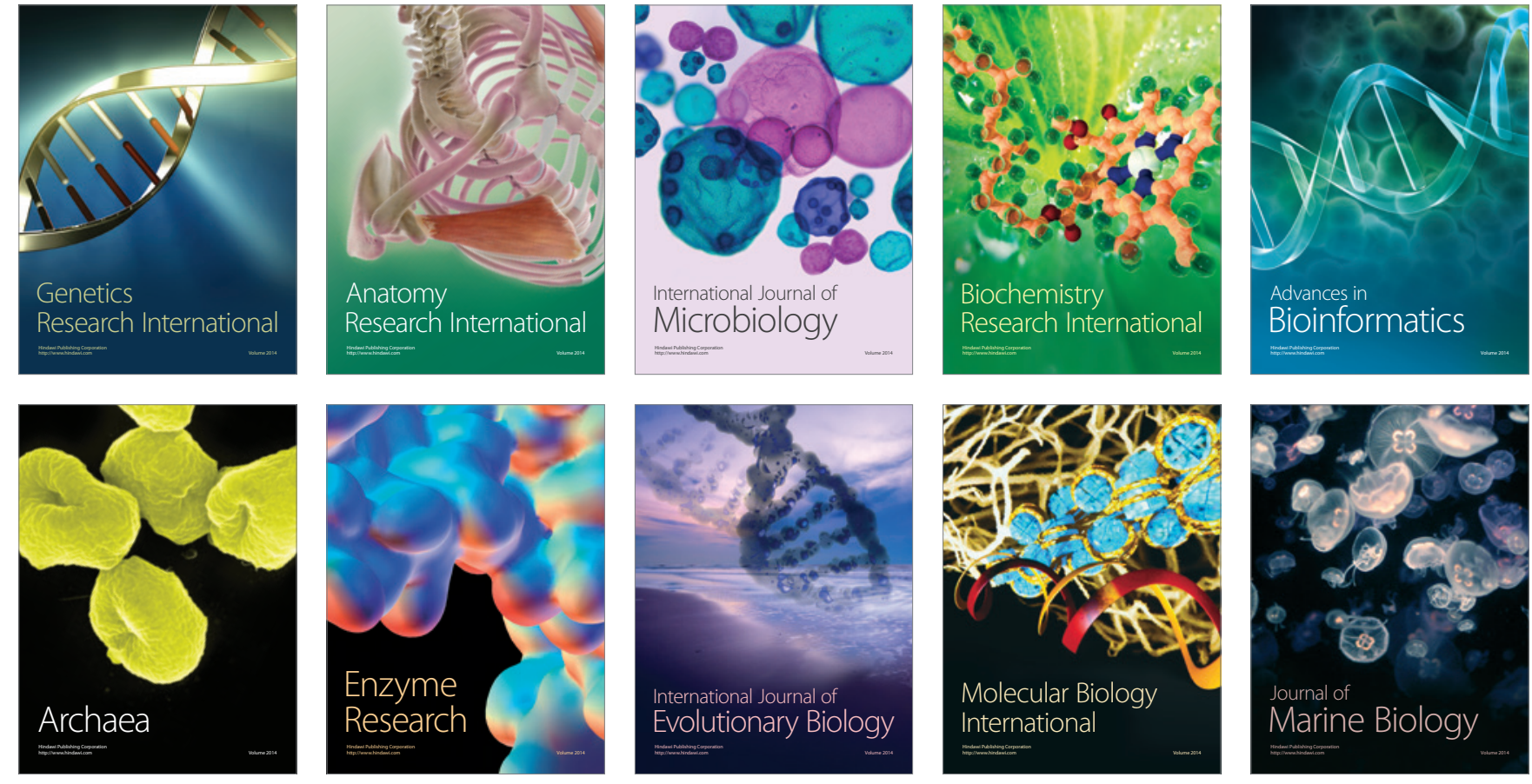